apuntesuniversitarios.upeu.edu.pe

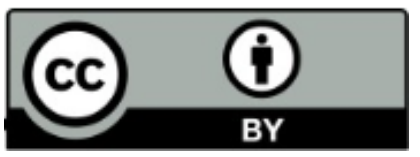

Apuntes Universitarios, 2020: 10(1), Enero-Marzo

ISSN: 2304-0335 DOI: https://doi.org/10.17162/au.v10i1.416

\title{
Percepción del diario "trome" en conductores de transporte público de lima metropolitana
}

\author{
Perception of the Trome Newspaper in public transportation drivers \\ in the City of Lima, Perú \\ Evelyn Lizeth Chávez Espinoza ${ }^{1}$ \\ Dirección Nacional de Inteligencia de Perú, Perú ${ }^{1}$ \\ Orcid ID: https://orcid.org/0000-0002-5473-809X ${ }^{1}$
}

Recibido: 12 de junio de 2019

Aceptado: 02 de setiembre de 2019

\begin{abstract}
Resumen
El estudio tiene por objetivo relacionar la percepción hacia la forma y contenido del diario Trome por el tipo de conductores de transporte público de Lima Metropolitana. Por ello, se empleó una encuesta de 25 ítems de diseño de escala de tipo Likert con validez y confiabilidad de .896 en 153 conductores de la modalidad de transporte regular y 83 de taxi de Lima Metropolitana previo consentimiento consentido. Los resultados evidencian que existe asociación entre la dicotomía contenido y forma del mensaje periodístico con el tipo de conductor de transporte público. Es así que los conductores de transporte regular presentan una mayor relación al mensaje mediante la forma centrándose en los colores, imágenes y titulares llamativos, dejando de prestar atención a temas de fondo porque - según manifiestan — se encuentran convencidos de la veracidad del diario Trome. En cambio, el conductor de taxi se asocia también al contenido del mensaje, pero en mínima proporción. En términos generales, ambos grupos no advierten mensajes implícitos con facilidad, por lo que se concluye que la gran influencia del diario se da por la forma, pues un sector limitado de transportistas se percata del mensaje implícito.
\end{abstract}

Palabras claves: Percepción, mensaje, conductores, diario Trome

${ }^{1}$ Correspondencia al autor

E-mail: lizethy1010@gmail.com 


\begin{abstract}
The study aims to relate the perception to the form and content of the newspaper Trome by the type of public transport drivers of Metropolitan Lima. Therefore, a survey of 25 Likert-type scale design items with validity and reliability of .896 was used in 153 drivers of the regular transport mode and 83 of the Metropolitan Lima taxi prior to consent. The results show that there is an association between the dichotomy content and form of the journalistic message with the type of public transport driver. Thus, regular transport drivers have a greater relationship to the message through the form focusing on the colors, images and eye-catching headlines, stop paying attention to background issues because - as they say - they are convinced of the truth of the newspaper Trome. Instead, the taxi driver is also associated with the content of the message, but in a minimal proportion. In general terms, both groups do not notice implicit messages with ease, so it is concluded that the great influence of the newspaper is given by the form, since a limited sector of carriers is aware of the implicit message.
\end{abstract}

Keywords: Perception, message, drivers, Trome newspaper

\title{
Introducción
}

Diversos investigadores sociales, periodistas y líderes de opinión sostienen que la objetividad no existe en los medios de comunicación, ya que su contenido posee filtros informativos de carácter empresarial, económico y político (Acevedo, 2013); los cuales son promovidos por sus principales auspiciadores y/o accionistas (Dario, 2001). Para los especialistas, pretender la objetividad periodística es como creer posible capturar y congelar el instante que huye, porque el mismo evento o situación puede recibir diferentes interpretaciones por una misma persona (Berlo, 2000) llegando muchas veces a convertir las afirmaciones en verdades temporales (Dario, 2001). Esta falsa objetividad suele ser aprovechada por los medios de comunicación, los cuales pretenden informar con la verdad y cumplir un rol fiscalizador en pro del desarrollo de la democracia; sin esto, no tendrían la excusa necesaria para autodenominarse "el cuarto poder" de un estado democrático (Godoy, 2017).

El Instituto Prensa y Sociedad del Perú (2008) afirma que "En América latina se registran altos márgenes de concentración mediática, que superan los estándares considerados aceptables" (Becerra y Mashini, 2018). Nuestro país no es ajeno a esta realidad, por lo que los medios televisivos, la prensa y la radio presentan altos niveles de concentración mediática; esto evidencia su restricción a la libertad de expresión, principalmente a la información plural y veraz (Acevedo, 2011). 
Lamentablemente, en el Perú no existe alguna legislación de medios de comunicación (Alarcon, 2014) que regule la participación de conglomerados informativos; esto se debe a la desconformidad que manifiesta el grupo informativo más predominante mediante campañas de sensibilización, donde sostienen que la nueva iniciativa vulnera la libertad de expresión, la cual se encuentra amparada en el Art. 2 inciso 4 de la Constitución Política del Perú (República, 2018).

Por otro lado, en el 2003, el Grupo El Comercio se hizo del 54\% de acciones del Grupo Epensa. Para algunos analistas políticos, esta situación agudizó los niveles de concentración mediática, lo que significa la creación de una barrera que restringe el libre ejercicio del derecho a la comunicación plural en un espacio público "derecho que se encuentra cercenado por el desmedido crecimiento del Grupo El Comercio" (Acevedo, 2013).

En la actualidad, el Grupo El Comercio ejerce la titularidad del 80\% del mercado de prensa peruana y es propietario de los diarios: El Comercio, Perú 21, Trome, Gestión, Depor, Ojo, Correo, Ajá y El Bocón (Maldonado, 2013). Esta concentración mediática genera una situación de dominio y poder, propia de un comportamiento monopólico, lo que se puede considerar un hecho de concentración informativa que posibilita una base referencial importante en la construcción de percepción de la población (Alvarez, 2014).

En tanto, ya que la percepción social es una variable psicosocial que se encuentra inmersa en la opinión, el investigador Berlo sostiene que el ser humano organiza sus percepciones e impone una estructura respecto a los datos sensoriales que recibe. Es decir, el sujeto proporciona subjetividad a las cosas mediante dos maneras muy marcadas (Berlo, 2000). La primera corresponde al número de posibles percepciones y observaciones, el cual resulta infinito. La segunda, sostiene que nunca podremos observar todas las cosas por completo. Asimismo, Berlo afirma que "la percepción es selectiva y que percibimos para influirnos" de manera que, la percepción depende de la clase de impresiones que tengamos y los propósitos que nos hayan inducido los emisores de información, ya que percibimos algunas cosas y otras no (Berlo, 2000). Se estructuran las percepciones a fin de ajustarlas a nuestros juicios, experiencias y valoraciones, las cuales se hallan entrelazadas.

Por otro lado, según reportes de la Unesco publicadas en la revista de Harvard (2014), el $71 \%$ de peruanos elige leer periódicos y el 35\% restante libros; esto demuestra un mayor interés hacia los medios de comunicación escrita por su estilo informativo, redacción, colores e imágenes que refuerzan su mensaje. Ante esto, Igartúa (2015), señala que los 
mensajes de los medios de comunicación tienen la capacidad de provocar emociones o cambiar el estado de ánimo de las personas; de allí su importancia, porque influencia a nivel emocional.

Por su parte, el diario Trome es un medio de comunicación impreso de circulación nacional que goza de aceptación en un público masivo, no sólo por su bajo costo, sino por la manera como presenta o cuenta la noticia con un lenguaje ameno y sencillo para sus consumidores, estos generalmente con educación básica, que buscan entretenerse e informarse. Además, según estudios realizados en julio del 2016 por la Compañía Peruana de Estudios de Mercado y de Opinión Pública (CPI), el diario Trome lidera el ranking de lectoría en Lima Metropolitana y constituye el diario más vendido a nivel nacional. Según la empresa Kantar Ibope, el diario Trome logró, en diciembre 2016, una lectoría de dos millones y medio, batiendo récord en ventas a nivel nacional e internacional (Ponce, 2017).

En este contexto, la presente investigación busca describir las percepciones hacia la forma y contenido del diario Trome en conductores de transporte público, en las modalidades de transporte regular y taxi, de Lima Metropolitana. El objetivo es describir las diferencias en las percepciones hacia el aspecto de Trome en su forma (mensaje explícito) y contenido de información (mensaje implícito).

\section{Método}

\section{Tipo y diseño de investigación}

La investigación es de tipo asociativo, entre la percepción hacia la forma y la percepción hacia el contenido del diario Trome por el tipo de conductores de transporte público de Lima Metropolitana (Sanchez y Reyes, 2015). En este aspecto, se ha visto por conveniente la utilización del chi cuadrado para advertir las diferencias significativas entre la dicotomía forma y contenido.

\section{Población y muestra}

La población de estudio está formada por conductores de transporte público de las modalidades de transporte regular y taxi de Lima Metropolitana, seleccionados de forma intencional y teniendo como criterio la inclusión empresas formales, centros de formación 
(Universidad Nacional de Ingeniería y Brevetes Perú) e interés de los conductores por cooperar con la investigación.

La muestra comprende a 239 conductores de transporte público entre los cuales se encuentran 153 conductores pertenecientes a la modalidad de transporte regular (buses, “custer" y “combis") y 86 conductores de la modalidad de taxi en Lima Metropolitana. A su vez, los conductores se caracterizan por ser de género masculino. Sus edades están comprendidas de 20 a 74 años de edad $(\mathrm{M}=41.42, \mathrm{DS}=11.79)$ para el caso de los conductores de transporte regular, y de 23 a 71 años de edad $(\mathrm{M}=45.14, \mathrm{DS}=10.20)$ para el caso de conductores de taxi de Lima Metropolitana.

Con respecto al grado académico de los conductores, el $52.2 \%$ posee estudios completos de educación secundaria, el $20.55 \%$ formación técnica superior y el $7.3 \%$ estudios universitarios, siendo los taxistas los que cuentan con mayor nivel académico (34.8\%). El nivel de experiencia es mayor a 15 años, en el caso de los taxistas alcanza el $61 \%$ de encuestados y en los conductores de transporte regular el $38.6 \%$.

\section{Tabla 1}

Distribución de población de la muestra de conductores de Lima Metropolitana. Características de la muestra en conductores.

\begin{tabular}{lcccc}
\hline \multicolumn{1}{c}{ Variable sociodemográfica } & \multicolumn{2}{c}{ Transporte regular } & \multicolumn{2}{c}{ Taxi metropolitano } \\
& Frecuencia & Porcentaje & Frecuencia & Porcentaje \\
\hline Sexo & 153 & 100.0 & 85 & 98.8 \\
Varón & 0 & --- & 1.2 \\
Mujer & & & 1 & 7.0 \\
Edad (años) & 39 & 25.5 & 31.4 \\
$20-30$ & 36 & 23.5 & 27 & 32.6 \\
$31-40$ & 36 & 23.5 & 28 & 20.9 \\
$41-50$ & 34 & 22.2 & 18 & 8.1 \\
$51-60$ & 8 & 5.2 & 7 & 2.3 \\
$61-74$ & & & & 1.2 \\
Grado de instrucción & 4 & 2.6 & 2 & 12.8 \\
Primaria incompleta & 5 & 3.3 & 1 & 48.8 \\
Primaria completa & 27 & 17.6 & 42 & \\
Secundaria incompleta & 85 & 55.6 & & \\
Secundaria completa & & & & \\
\end{tabular}




$\begin{array}{lcccc}\text { Técnico superior } & 22 & 14.4 & 23 & 26.7 \\ \text { Superior universitaria } & 10 & 6.5 & 7 & 8.1 \\ \text { Años de experiencia transporte } & & & & \\ \text { Menos de un año } & 19 & 12.4 & 4 & 4.7 \\ \text { De } 1 \text { a } 5 \text { años } & 33 & 21.6 & 16 & 18.6 \\ \text { De 6 a 15 años } & 42 & 27.5 & 13 & 15.1 \\ \text { Más de } 15 \text { años } & 59 & 38.6 & 53 & 61.6\end{array}$

\section{Categoría de licencia de conducir}

\begin{tabular}{lcccc} 
AI-A & --- & -- & 10 & 11.6 \\
AII-A & 2 & 1.4 & 24 & 27.9 \\
AII-B & 45 & 29.4 & 35 & 40.8 \\
AIII-A & 40 & 26.1 & 6 & 6.9 \\
AIII-C & 66 & 43.1 & 11 & 12.8 \\
\hline & 153 & 100.0 & 86 & 100.0 \\
\hline
\end{tabular}

\section{Técnicas e instrumentos}

La técnica usada en esta investigación es la encuesta y el instrumento empleado es la "Encuesta de percepción hacia la forma y el contenido en conductores de transporte público de Lima Metropolitana" el cual consta de 26 ítems. Dicho instrumento ha sido diseñado para fines del presente estudio y busca evaluar dos aspectos: las percepciones hacia el aspecto de forma (mensaje explícito) del diario Trome y las percepciones hacia contenido de información (mensaje implícito) del mismo.

La confiabilidad por consistencia interna del instrumento se determina a través del coeficiente alfa de Cronbach (Kerlinger y Lee, 2002). Un análisis preliminar del instrumento alcanza un alfa de Cronbach de .893 , indicando un nivel elevado de consistencia interna (Murphy y Davishofer, 1991; citado en Hogan, 2015). Los índices de correlación ítem-test en gran parte de los ítems son superiores a .200 con excepción del ítem 26. Al realizarse un segundo análisis (análisis final), el alfa de Cronbach se eleva ligeramente a .896. En relación con el componente morfológico y de contenido, los coeficientes alfa de Cronbach son .832 y .800, respectivamente (ver Tabla 2).

Tabla 2 
Análisis de confiabilidad en la encuesta de percepción hacia la forma y el contenido en conductores de transporte público de Lima Metropolitana $(N=239)$

\begin{tabular}{lcccc}
\hline & \multicolumn{2}{c}{ Análisis preliminar } & \multicolumn{2}{c}{ Análisis final } \\
\cline { 2 - 5 } & $\mathrm{N}$ & $\alpha$ & $\mathrm{N}$ & $\alpha$ \\
\hline Percepción social y análisis de contenido & 26 & .727 & 25 & .896 \\
Componente de forma & --- & --- & 16 & .832 \\
Componente de contenido & --- & --- & 9 & .800 \\
\hline
\end{tabular}

Nota: N, número de ítems; $\alpha$, alfa de Cronbach

La aplicación del instrumento de investigación es uniforme para todos los grupos, considerando que a cada participante se le hizo entrega de un ejemplar del diario de la fecha de la encuesta, un lapicero y un ejemplar del instrumento para que plasmen su percepción sobre aspectos de forma y contenido del diario en 30 minutos aproximadamente. Luego, la información fue procesada y analizada mediante una base de datos en SPSS versión 22.

\section{Resultados}

Los resultados son expuestos de acuerdo al objetivo del presente estudio: describir las diferencias en las percepciones hacia el aspecto de forma (mensaje explícito) y contendido de información (mensaje implícito) del diario Trome. Estos dos aspectos son analizados como características de forma y características de contenido, respectivamente. Adicionalmente, se establecen comparaciones entre conductores de transporte regular y conductores del taxi metropolitano a fin de determinar las diferencias entre las percepciones en ambos grupos de encuestados.

De acuerdo con la Tabla 3, las noticias más destacadas en el diario, para ambas muestras (conductores de transportes regular y de taxi metropolitano) son de farándula, seguida de las noticias policiales, deportivas y políticas. Por otro lado, existen diferencias significativas en las noticias de tipo deportivas, donde los conductores de transportes regular las consideran más importantes con respecto a los conductores de taxi metropolitano.

\section{Tabla 3}

Tipo de noticias destacadas en la portada del diario Trome en conductores ( $\mathrm{N}=239)$

\begin{tabular}{|c|c|c|c|c|}
\hline \multirow{2}{*}{ Tipo de noticias } & \multicolumn{2}{|c|}{ Transporte regular } & \multicolumn{2}{|c|}{ Taxi metropolitano } \\
\hline & Frecuencia & Porcentaje & Frecuencia & Porcentaje \\
\hline
\end{tabular}




\begin{tabular}{lcccc}
\hline (P1) Policiales & & & & \\
Totalmente de acuerdo & 45 & 29.4 & 47 & 54.4 \\
De acuerdo & 26 & 45.1 & 7 & 8.1 \\
Desacuerdo & 13 & 8.5 & 11 & 12.8 \\
Totalmente en desacuerdo & & & & \\
(P2) Farándula & 62 & 40.5 & 39 & 45.3 \\
Totalmente de acuerdo & 59 & 38.6 & 32 & 37.2 \\
De acuerdo & 21 & 13.7 & 7 & 8.1 \\
Desacuerdo & 11 & 7.2 & 8 & 9.3 \\
Totalmente en desacuerdo & & & & \\
(P3) Políticas & 38 & 24.8 & 12 & 14.0 \\
Totalmente de acuerdo & 64 & 41.8 & 38 & 44.2 \\
De acuerdo & 33 & 21.6 & 22 & 25.6 \\
Desacuerdo & 18 & 11.8 & 14 & 16.3 \\
Totalmente en desacuerdo & & & & \\
(P4) Deportivas* & 37 & 24.2 & 9 & 10.5 \\
Totalmente de acuerdo & 69 & 45.1 & 43 & 50.0 \\
De acuerdo & 36 & 23.5 & 19 & 22.1 \\
Desacuerdo & 11 & 7.2 & 15 & 17.4 \\
Totalmente en desacuerdo & 153 & 100.0 & 86 & 100.0 \\
\hline & & & & \\
\hline & & & 9 & \\
\hline
\end{tabular}

Nota: *diferencias significativas al $.05\left(X^{2}=11.304, g l=3, p=.012\right)$, entre conductores de transporte regular y conductores del taxi metropolitano.

En relación con las características de la portada del diario, ver Tabla 4. Aquí se muestra que los conductores están acuerdo con que la portada del diario presenta titulares llamativos, fotografías "estupendas" con colores atractivos, y siendo el color naranja distintivo de un diario popular de circulación nacional. Se determina también diferencias significativas respecto a la presencia de noticias importantes en la portada del diario, donde los conductores de transporte regular están de acuerdo, mientras que los de taxi metropolitano están en desacuerdo.

\section{Tabla 4}

Características de forma en la portada de un diario Trome en conductores $(N=239)$ 


\begin{tabular}{|c|c|c|c|c|}
\hline \multicolumn{5}{|c|}{ (P5) Noticias más importantes* } \\
\hline Totalmente de acuerdo & 37 & 24.2 & 14 & 16.3 \\
\hline De acuerdo & 61 & 39.9 & 20 & 23.3 \\
\hline Desacuerdo & 37 & 24.2 & 30 & 34.9 \\
\hline Totalmente en desacuerdo & 18 & 11.8 & 22 & 25.6 \\
\hline \multicolumn{5}{|l|}{ (P6) Titulares llamativos } \\
\hline Totalmente de acuerdo & 52 & 34.0 & 30 & 34.9 \\
\hline De acuerdo & 78 & 51.0 & 45 & 52.3 \\
\hline Desacuerdo & 19 & 12.4 & 5 & 5.8 \\
\hline Totalmente en desacuerdo & 4 & 2.6 & 6 & 7.0 \\
\hline \multicolumn{5}{|c|}{ (P7) Fotografías "estupendas" } \\
\hline Totalmente de acuerdo & 29 & 19.0 & 6 & 7.0 \\
\hline De acuerdo & 57 & 37.3 & 31 & 36.0 \\
\hline Desacuerdo & 44 & 28.8 & 30 & 34.9 \\
\hline Totalmente en desacuerdo & 23 & 15.0 & 19 & 22.1 \\
\hline (P8) Colores atractivos & & 0.0 & & 0.0 \\
\hline Totalmente de acuerdo & 33 & 21.6 & 23 & 26.7 \\
\hline De acuerdo & 95 & 62.1 & 50 & 58.1 \\
\hline Desacuerdo & 16 & 10.5 & 8 & 9.3 \\
\hline Totalmente en desacuerdo & 9 & 5.9 & 5 & 5.8 \\
\hline \multicolumn{5}{|c|}{ (P9) Color naranja como identificador } \\
\hline Totalmente de acuerdo & 51 & 33.3 & 20 & 23.3 \\
\hline De acuerdo & 83 & 54.2 & 48 & 55.8 \\
\hline Desacuerdo & 12 & 7.8 & 15 & 17.4 \\
\hline Totalmente en desacuerdo & 7 & 4.6 & 3 & 3.5 \\
\hline & 153 & 100.0 & 86 & 100.0 \\
\hline
\end{tabular}

Nota: *diferencias significativas al $.01\left(X^{2}=14.624, g l=3, p=.002\right)$, entre conductores de transporte regular y conductores del taxi metropolitano.

Las características de contenido de las páginas interiores del diario, ver Tabla 5, en ambas muestras, se determina en mayor grado de acuerdo sobre la facilidad en la lectura y entendimiento. Asimismo, se detectan diferencias significativas respecto si las noticias de la sección deportes son emocionantes: los conductores de transporte regular presentan una tendencia a estar totalmente de acuerdo, pero los conductores de taxi metropolitana presentan tendencia a estar en desacuerdo. Además, en relación con el análisis de contenido de las páginas interiores del diario, en ambas muestras se aprecia un mayor grado de acuerdo sobre las secciones "La calle esta dura", "Karry", de trasfondo político. En contraste, hay 
diferencias significativas en los análisis de contenido sobre la veracidad de la sección "La seño María” y de la sección “Actualidad”. En ambas, los conductores de transporte regular presentaron una tendencia a estar totalmente de acuerdo, pero en los conductores de taxi metropolitana hubo tendencia a estar en desacuerdo.

\section{Tabla 5}

Características de contenido de las páginas interiores del diario Trome en conductores $(\mathrm{N}=239)$

\begin{tabular}{|c|c|c|c|c|}
\hline \multirow{2}{*}{ Características de contenido } & \multicolumn{2}{|c|}{ Transporte regular } & \multicolumn{2}{|c|}{ Taxi metropolitano } \\
\hline & Frecuencia & Porcentaje & Frecuencia & Porcentaje \\
\hline \multicolumn{5}{|l|}{ (P10) Facilidad en la lectura } \\
\hline Totalmente de acuerdo & 65 & 42.5 & 36 & 41.9 \\
\hline De acuerdo & 82 & 53.6 & 49 & 57.0 \\
\hline Desacuerdo & 1 & 0.7 & 1 & 1.2 \\
\hline Totalmente en desacuerdo & 5 & 3.3 & 0 & 0.0 \\
\hline \multicolumn{5}{|l|}{ (P11) Fácil entendimiento } \\
\hline Totalmente de acuerdo & 53 & 34.6 & 29 & 33.7 \\
\hline De acuerdo & 87 & 56.9 & 53 & 61.6 \\
\hline Desacuerdo & 8 & 5.2 & 2 & 2.3 \\
\hline Totalmente en desacuerdo & 5 & 3.3 & 2 & 2.3 \\
\hline \multicolumn{5}{|l|}{ (P12) "La seño María" dice la verdad* } \\
\hline Totalmente de acuerdo & 35 & 22.9 & 6 & 7.0 \\
\hline De acuerdo & 57 & 37.3 & 44 & 51.2 \\
\hline Desacuerdo & 43 & 28.1 & 30 & 34.9 \\
\hline Totalmente en desacuerdo & 18 & 11.8 & 6 & 7.0 \\
\hline \multirow{2}{*}{\multicolumn{5}{|c|}{$\begin{array}{l}\text { (P13) "La calle esta dura" y "Karry" tienen } \\
\text { trasfondo político }\end{array}$}} \\
\hline & & & & \\
\hline Totalmente de acuerdo & 31 & 20.3 & 12 & 14.0 \\
\hline De acuerdo & 68 & 44.4 & 49 & 57.0 \\
\hline Desacuerdo & 38 & 24.8 & 18 & 20.9 \\
\hline Totalmente en desacuerdo & 16 & 10.5 & 6 & 7.0 \\
\hline \multicolumn{5}{|c|}{ (P14) “Actualidad" describe la realidad** } \\
\hline Totalmente de acuerdo & 38 & 24.8 & 8 & 9.3 \\
\hline De acuerdo & 75 & 49.0 & 52 & 60.5 \\
\hline Desacuerdo & 28 & 18.3 & 21 & 24.4 \\
\hline Totalmente en desacuerdo & 12 & 7.8 & 5 & 5.8 \\
\hline
\end{tabular}




\begin{tabular}{lcccc} 
Totalmente de acuerdo & 50 & 32.7 & 11 & 12.8 \\
De acuerdo & 71 & 46.4 & 40 & 46.5 \\
Desacuerdo & 24 & 15.7 & 27 & 31.4 \\
Totalmente en desacuerdo & 8 & 5.2 & 8 & 9.3 \\
(P16) "Fiesta (farándula)" son entretenidas & & & 10.5 \\
Totalmente de acuerdo & 25 & 16.3 & 9 & 52.3 \\
De acuerdo & 68 & 44.4 & 45 & 22.1 \\
Desacuerdo & 35 & 22.9 & 19 & 13.1 \\
Totalmente en desacuerdo & 25 & 16.3 & 13 & 100.0 \\
\hline
\end{tabular}

Nota: *diferencias significativas al .01 $\left(X^{2}=12.718, g l=3, p=.005\right)$; **diferencias significativas al .05 $\left(X^{2}=9.584, g l=3, p=.022\right) ; * * *$ diferencias significativas al $.01\left(X^{2}=16.264, g l=3, p=.001\right)$; todos ellos, entre conductores de transporte regular y conductores del taxi metropolitano.

En la Tabla 6 se presenta un análisis de contenido general del diario, que refleja un grado de acuerdo en la veracidad del diario, y es crítico con el gobierno actual, para ambas muestras. En contraste, se aprecian diferencias significativas en si los conductores de ambas muestras se mantienen informados debido al contenido del diario, presentando una tendencia a totalmente de acuerdo en los conductores de transporte regular, mientras que los conductores de taxi metropolitano hubo tendencia a estar en desacuerdo.

\section{Tabla 6}

Características de contenido general de un diario popular de circulación nacional en conductores $(N=239)$

\begin{tabular}{lcccc}
\hline \multicolumn{1}{c}{ Características de contenido } & \multicolumn{2}{c}{ Transporte regular } & \multicolumn{2}{c}{ Taxi metropolitano } \\
& Frecuencia (f) & Porcentaje (\%) & Frecuencia (f) & Porcentaje (\%) \\
\hline (P21) Mantiene informado* & & & & 15.1 \\
Totalmente de acuerdo & 45 & 29.4 & 13 & 51.2 \\
De acuerdo & 75 & 49.0 & 44 & 18.6 \\
Desacuerdo & 20 & 13.1 & 16 & 15.1 \\
Totalmente en desacuerdo & 13 & 8.5 & 12 & 14.0 \\
(P24) Dice la verdad & & & 50.0 \\
Totalmente de acuerdo & 36 & 23.5 & 43 & 25.6 \\
De acuerdo & 75 & 49.0 & 22 & 10.5 \\
Desacuerdo & 32 & 20.9 & 9 & 5.5
\end{tabular}


(P25) Es crítico del gobierno actual

\begin{tabular}{lcccc} 
Totalmente de acuerdo & 19 & 12.4 & 10 & 11.6 \\
De acuerdo & 61 & 39.9 & 34 & 39.5 \\
Desacuerdo & 53 & 34.6 & 26 & 30.2 \\
Totalmente en desacuerdo & 20 & 13.1 & 16 & 18.6 \\
\hline
\end{tabular}

Nota: *diferencias significativas al $.05\left(X^{2}=8.023, g l=3, p=.046\right)$, entre conductores de transporte regular y conductores del taxi metropolitano.

\section{Discusión}

Para la discusión se toman en cuenta algunas teorías de comunicación y de percepción que ayudan a conceptualizar de una forma más minuciosa, la apreciación hacia la forma y contenido en un medio de comunicación impreso.

El emisor o fuente es aquel sujeto que construye el mensaje (Prieto, 1982). En el presente caso, es el medio de comunicación lo que modela el tratamiento de las informaciones a través de su línea informativa, compuesta por los principales accionistas o dueños del medio de comunicación (Fernandez, Garcia y Agustin, 2001). El diario Trome, a diferencia de otros medios de comunicación del mismo formato, realiza periódicamente estudios de mercado con la finalidad detectar nuevos intereses en sus lectores a fin de ofrecerles productos de acuerdo a sus necesidades y fidelizarlos (Gestion, 2013). En este aspecto, el psicólogo peruano Cárdenas (1995), señala: "cuando el emisor posee intenciones o fines como el de influir deliberadamente en su auditorio su mensaje será especial, elaborado, subliminal y encubierto".

El receptor o destinatario del diario está conformado por el sujeto o grupo de sujetos que reciben el mensaje y lo decodifican de acuerdo con sus actitudes, conocimientos, sistema social y cultural (Berlo, 2000). Para esta investigación los receptores son los lectores y/o clientes del diario Trome, los cuales - según un ex directivo del diario en mención-se caracterizan por ser clientes de tipo "progresista", siendo los conductores de transporte regular y de taxi la población prototipo del diario mencionado.

En el estudio, el 93\% de los conductores afirmaron ser clientes del diario Trome y que lo compran frecuentemente porque creen en su veracidad, siendo los conductores de transporte regular los más convencidos (72.5\%), seguidos de los taxistas (64\%) que también mostraron una tendencia positiva con la premisa, pero en menor proporción. Esto indica que un gran sector de los transportistas se encuentra convencido que el diario Trome informa con la verdad. 
Asimismo, existe un reducido sector de transportistas que indican no creer en la información que brinda el diario Trome. Este pequeño sector está compuesto mayoritariamente por conductores de transporte de taxi, lo que nos ayuda a inferir que mantienen una percepción crítica y están predispuesto a detectar en mayor medida los mensajes implícitos del diario Trome.

Por último, el mensaje es el elemento de comunicación construido por el emisor y dirigido al receptor considerando aspectos como el código y el tratamiento informativo (Berlo, 2000). Según Cárdenas (1995) el mensaje está referido al contenido que transmite el emisor, ya sean ideas, sentimientos o actitudes, elaborados de forma directa o indirecta. El mensaje directo, se caracteriza por ser "transparente y real"; mientras el mensaje indirecto "dice algo más de lo que dice", es decir, tiene un contenido entre líneas. Para estos casos, Cárdenas sugiere aplicar el análisis de contenido a fin de descubrir en mensaje encubierto y diferenciarlo del mensaje aparente que está escrito.

El mensaje explícito en el diario Trome está comprendido por la identificación de elementos como los titulares, el tipo de noticias, las imágenes, los colores, los textos, entre otros. Así resulta que, el $75.26 \%$ de los conductores de transporte regular y $66.34 \%$ de conductores de taxi se encuentran conformes con los estímulos que proporciona el diario Trome, siendo los conductores de transporte regular los que más se identifican con los estímulos brindados.

Con respecto al tipo de noticias que destaca el diario Trome en su portada, el $80.8 \%$ de conductores de transporte urbano señala que el medio de comunicación popular prioriza "noticias de espectáculos". Esta situación se denomina figura o forma y los conductores llegaron a percibirlo con naturalidad. Esto confirma la opinión de Ramírez y Marquina (2016): "La forma prima sobre el fondo haciendo que el diseño sea un fin en sí mismo con el único objetivo de capturar la atención del lector.” En este contexto, el diario Trome pertenece a la tipología de "prensa popular sensacionalista", que cumple con el objetivo de entretener y magnificar mediante la forma el valor informativo de la realidad.

\section{Conclusiones}

1. Existe asociación entre el mensaje de forma con el tipo de conductor; por ello, los conductores de transporte público de la modalidad de transporte regular y de taxi de Lima 
Metropolitana perciben mayoritariamente elementos de forma y/o mensajes explícitos ya que se sienten identificados con los estímulos que brinda el diario Trome.

2. La atención de los conductores de transporte regular se centra en los elementos de forma cómo, colores, imágenes y titulares llamativos, dejando de prestar atención a temas de fondo, ya que señalan estar convencidos de que el diario Trome les informa con la verdad.

3. En el caso de los conductores de taxi, aunque muestran algunas discrepancias con los estímulos que brinda el diario Trome, no advierten con facilidad sus mensajes implícitos.

4. Se estima que el nivel educativo básico de ambos grupos de conductores favorece a la permeabilidad de conceptos que se encuentran modelados por el diario Trome, el cual se evidencia en la redacción de forma descriptiva e interpretativa de sus noticias.

5. El diario Trome ha logrado encubrir aún más sus mensajes implícitos a tal manera que su lector frecuente cree, en gran medida, en su veracidad informativa. Esto permite afirmar que el medio de comunicación influye en la construcción de opinión pública. En ese sentido, el lector estaría aceptando las opiniones del diario como verdades absolutas dejando de lado la posibilidad de contrastar su contenido.

\section{Referencias}

Acevedo J. (2011). La concentración mediática es la principal amenaza para la libertad de expresión. IDL Revista (214).

Acevedo, J. (2013). La concentración mediática no es un asunto de privados (Vol. 191). Lima, Perú: Quehacer.

Alarcón, L. (2014). Una ley de medios para el Perú. Un debate perpetuo. Alaic. Lima: PUCP.

Álvarez, A. (2014). Concentración de medios un fenomeno muy grave para la democracia y libertad informativa. PUCP.

Andreu, J. (1998). Las tecnicas de análisis de contenido. España: Fundación Centro de Estudios Andaluces.

Becerra M. y Mashini G. (2018). Concentracion de los medios en America Latina: Tendencias de un nuevo siglo. Contratexto (18), 51.

Becerra, C. (2014). Una propuesta al debate sobre la concentración de medios en el Perú: El caso de la fusión de El Grupo El Comercio con el grupo EPENSA (artículo inédito). Piura, Perú: Repositorio Institucional PIRHUA. 
Berlo, D. (2000). El proceso de la comunicación. Introducción a la teoría y a la práctica (3 ed.). Buenos Aires: Ateneo.

Cárdenas, C. (1995). Texto de análisis de contenido. Chorrillos: Escuela Nacional de Inteligencia.

CPI. (2016). Estudio de lectoria de diarios en Lima y 15 principales ciudades. Lima.

Darío, J. (2001). La objetividad periodistica: Utopía y realidad. (74 ed.). Revista Latinoamericana de Comunicación Chasqui.

Dávila, K. (2017). Análisis del tratamiento periodistico de las portadas del diario Trome publicadas en Lima Metropolitana entre enero y abril 2017 (Tesis de licenciatura). Lima, Perú: Universidad Cesar Vallejo.

Ernesto, C. (2012). Periodismo objetivo o subjetivo, una falsa dicotomía. Congreso de Periodismo y medios de comunicacion. Argentina.

Fernández, T., García, A. (2001). Medios de Comunicacion, sociedad y educación. Castilla: Ediciones de la Universidad de Castilla - La Mancha.

Gestión, D. (15 de 10 de 2013). Trome: La estrategia para convertir un diario en el más leído de habla hispana. Diario Gestion.

Godoy, J. (2017). Entre liberales y conservadores. ¿Que explica los cambios en la cobertura política del diario El Comercio durante el siglo XXI? (Tesis de maestría). Lima: Universidad Católica del Perú.

Hallin D. y Mancini P. (2007). Un estudio comparado de los medios en América Latina. (7 ed.). Revista Tendencia.

Hogan, T. (2015). Pruebas psicologicas. Mexico: Manual moderno.

Igartua, J. (2015). Psicología Social de los medios de comunicación. Madrid: Medica Panamericana.

Kerlinger, F. y. (2002). Investigación del comportamiento. Mexico: McGraw Hill.

Maldonado, P. (2013). Revista IDL 234. Obtenido de https://revistaideele.com/ideele/content/grupo-el-comercio-un-pulpo-de-los-mediosde-comunicaci\%C3\%B3n

Martínez, H. (2004). La influencia de los medios de comunicación en el proceso de aprendizaje. Comunicar, 183-188.

Ponce, L. (2017). El impacto de la portada del diario Trome en los lectores de entre las edades de 18 a 50 años. Lima, Perú: Universidad Inca Garcilaso de la Vega. 
Prieto, D. (1982). Elementos para el analisis de mensajes. Instituto Latinoamericano de la Comunicacion educativa.

Ramírez M. y Marquina, O. (2016). Comunicación y diseño en la prensa impresa. Lima, Perú: Fondo Editorial PUCP.

República, D. L. (14 de junio de 2018). Orenizaciones de prensa rechazan aprobacion le ley mordaza .

Sánchez, H. y Reyes, C. (2015). Metodologia y diseños en la investigación cientifica. Lima: Vision Universitaria. 